\title{
Matematiikan kuusi osaa: David Tallin matematiikan kolmen maailman viitekehyksen laajentaminen Juha Oikkosen matematiikan kaksilla kasvoilla
}

Jani Hannula

Matematiikan ja tilastotieteen laitos, Helsingin yliopisto •jani.hannula@helsinki.fi

Tiivistelmä David Tallin matematiikan kolme maailmaa tarjoaa viitekehyksen matemaattisen ajattelun ja sen kehittymisen tarkasteluun. Tallin kolmen maailman viitekehyksen laajentaminen Juha Oikkosen "matematiikan kaksilla kasvoilla" tuottaa uuden, laajemman viitekehyksen, jossa tietyt näkökulmat matematiikan oppimiseen liittyvässä tutkimuksessa (kuten miniteoriat) asettuvat osaksi laajempaa kokonaisuutta. Oikkosen aiemmin hahmottelemalla ja tässä kirjoituksessa tarkemmin analysoidulla viitekehyksellä on selitysvoimaa myös esimerkiksi yksittäiseen matemaattiseen käsitteeseen liittyvän oppimisprosessin tarkastelun suhteen.

\section{Johdanto}

Esittelen tässä kirjoituksessa aluksi David Tallin matemaattista ajattelua ja sen kehittymistä kuvaavan matematiikan kolmen maailman viitekehyksen. Tall (2013) on pyrkinyt matematiikan kolmen maailman avulla kuvaamaan matemaattisen ajattelun kehittymistä varhaisesta lapsuudesta aina yliopistotason ajatteluun asti. Tarkempaan (esimerkiksi yksittäiseen käsitteeseen liittyvään) oppimisprosessin kuvaamiseen ja tutkimiseen tarvitaan jotain spesifisempää kuten APOS-teoria, joka jäsentää yksilön oppimista asteittain lähtien yksittäisistä teoista (actions) ja päätyen skeemojen (schemas) rakentumiseen (ks. Dubinsky, E. \& McDonald, M. A., 2001). Pyrin tässä kirjoituksessa osoittamaan, että Tallin kolmen maailman viitekehystä on mahdollista laajentaa yhdistämällä siihen J uha Oikkosen "matematiikan kahdet kasvot" (ks. Oikkonen, 2004). Oikkonen (2013) on hahmotellut näiden kahden viitekehyksen yhdistämistä. Pyrin tässä kirjoituksessa muotoilemaan tämän yhdistetyn viitekehyksen (esimerkin avulla) ja arvioimaan sen arvoa matemaattista ajattelua kuvaavana teoriana.

\section{David Tallin matematiikan kolme maailmaa}

Ajatellessamme matemaattisesti saatamme tehdä havaintoja esimerkiksi edessämme olevasta kuvasta, suorittaa opittuja symbolisia proseduureja tai tutkia formaalia matemaattista teoriaa. Nämä eri matemaattisen ajattelun aspektit ovat David Tallin matematiikan kolmen maailman näkökulman lähtökohdat (ks. Tall, 2004). Tallin jaottelu ei ole filosofinen positio tai teoria siitä, mitä matematiikka on, vaan yksinkertainen viitekehys sille, minkälaiset ajattelun aspektit ovat tai voivat olla läsnä, kun ihminen oppii matematiikkaa. Tallin matematiikan kolme maailmaa ovat 
1. käsitteellis-ruumiillinen/ilmenevä maailma (conceptual-embodied),

2. proseptuaalis-symbolinen maailma (proceptual-symbolic) ja

3. aksioomaattis-formaali maailma (axiomatic-formal).

Käytän näistä jatkossa nimiä ilmenevä, symbolinen ja formaali maailma. Mitä nämä maailmat sitten tarkoittavat? J os ajattelemme esimerkiksi summaa $1+2+3+\ldots+100$, voimme havaita, että se on sama kuin 50 -101. Luku 50 on puolet sadasta ja 101 on sama kuin $100+1$. Yleisemmin voidaankin laskea $n$ peräkkäistä luonnollista lukua yhteen kaavalla

$1+2+3+4+\cdots+n=\frac{n(n+1)}{2}$

Miten tämä matemaattinen totuus voi meille näyttäytyä tai miten sen voi keksiä? Ilmenevän maailman näkökulmasta se voi näyttäytyä esimerkiksi seuraavanlaisen kuvan avulla.

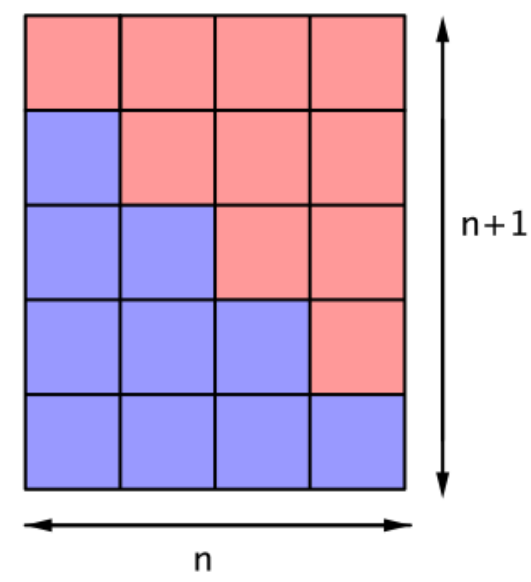

Kuvio 1 Summakaava Tallin 1. maailmassa

Kuvassa summa $1+2+3+4$ ruumiillistuu ja ilmenee punaisten tai sinisten ruutujen lukumääränä. Koska ruutuja on yhteensä $4 \cdot 5$ kappaletta ja lisäksi sinisiä ja punaisia ruutuja on yhtä paljon, on summan $1+2+3+4$ pakko olla puolet tulosta $4 \cdot 5$. Voimme "sielumme silmin" nähdä, että olipa ruutujen määrä mikä tahansa (n kappaletta), havaintomme pysyy samana: yhtälön

$1+2+3+4+\cdots+n=\frac{n(n+1)}{2}$ 
on pakko olla totta. Ilmenevässä maailmassa on siis kyse siitä, että matematiikkaa ymmärretään asioiden konkretisoituessa tavalla tai toisella (esineet, kuvat, mielikuvat, kehollinen kokeminen...). Tällaiset matematiikkakokemukset ovat mm. Varga- Neményimenetelmän (eli ns. unkarilaisen matematiikan) ydintä (ks. Lampinen, 2008).

Toisaalta asiaa voi ajatella symbolisen maailman näkökulmasta esimerkiksi merkitsemällä $S=1+2+3+4$ ja "laskemalla allekkain":

$S=1+2+3+4$

$S=4+3+2+1$

$2 S=5+5+5+5$

Siis on oltava $2 S=4 \cdot 5$, mikä tarkoittaa että $S=(4 \cdot 5) / 2$. Tämän voisi tietenkin tehdä myös yleisemmällä tasolla merkitsemällä $S_{n}=1+2+3+4+\ldots+n$ ja yleistämällä aikaisemman "geneerisen" esimerkin. Tämä matematiikan maailma näyttäytyy usein koulun matematiikan tunneilla ja myös korkeakouluissa matematiikkaa opiskellessa. Maailman nimessä esiintyvä sanaleikki "prosepti" viittaa sanoihin process ja concept; voimme ajatella symboleita pyöritellessämme sekä yhteenlaskun prosessia että lukujen yhteenlaskua käsitteenä. Proseptin käsite on peräisin Eddie Graylta ja David Tallilta (1991). Oppimisprosessia voidaan tämän dualiteetin pohjalta tarkastella samaan tapaan kuin APOS-teoriaa käyttäen: tiettyyn matemaattiseen käsitteeseen liittyvä ajattelu voi muuttua alkeellisesta "hienostuneemmaksi" (ks. Tall, 2013 s. 64).

Mikä sitten on formaalin maailman näkökulma esiteltyyn summakaavaan? Aksiomaattis-formaalissa maailmassa katsotaan nimensä mukaisesti matematiikkaa siitä näkökulmasta, mikä olisi ns. formalistisen matematiikkakuvan (ks. Mura, 1993) mukaista matematiikkaa: matematiikka perustuu sovittuihin aksioomiin, joista johdetaan deduktiivisesti uutta tietoa. Tässä tarkasteltava väite koskee matemaattisen teorian näkökulmasta luonnollisten lukujen joukkoa. Luonnolliset luvut määritellään matemaattisessa teoriassa esimerkiksi Peanon aksioomien avulla. Summakaavan väite voitaisiin formaalisti todistaa induktiotodistuksella, sillä Peanon aksioomissa on mukana ns. induktioaksiooma. Induktioaksiooma sanoo karkeasti ottaen, että luonnollisten lukujen joukko koostuu täsmälleen luvusta 0 ja tämän seuraajista (eli luvuista 1,2,3,4,...). Tästä aksioomasta seuraa se, että ns. induktioperiaatetta voidaan käyttää todistamaan väitteitä kaikille luonnollisille luvuille.

Väite todistettaisiin toteamalla aluksi, että väite $E(n)$, joka on yhtälö $1+2+3+4+\ldots+n=$ $\mathrm{n}(\mathrm{n}+1) / 2$ pätee, kun n=1. Tämä on itse asiassa melko helppo huomata, sillä

$1=\frac{2}{2}=\frac{1 \cdot 2}{2}=\frac{1(1+1)}{2}$ 
Tämän jälkeen todistettaisiin lause $E(n)=>E(n+1)$ (eli jos väite pätee arvolla $n$, niin se pätee myös arvolla $n+1)$. Tämän jälkeen induktioaksiooman perusteella tulos pätee kaikilla luonnollisilla luvuilla. "J ossittelulauseen" $\mathrm{E}(\mathrm{n})=\mathrm{E}(\mathrm{n}+1)$ todistus voisi näyttää esimerkiksi seuraavalta.

Oletetaan, että

$1+2+3+4+\cdots+n=\frac{n(n+1)}{2}$

Tällöin

$1+2+3+4+\cdots+n+(n+1)$

$=\frac{n(n+1)}{2}+(n+1)$

$=\frac{n(n+1)+2(n+1)}{2}$

$=\frac{(n+2)(n+1)}{2}$

$=\frac{(n+1)(n+2)}{2}$

$=\frac{(n+1)((n+1)+1)}{2}$

On huomattava, että tämä todistus sisältää itse asiassa paljon symbolisen maailman ajattelua. Vaikka Tallin maailmat ovat hierarkkiset siinä mielessä, että matematiikan oppiminen alkaa ilmenevän maailman havainnoista ja saavuttaa huippunsa kolmannen aksiomaattis-formaalissa ajattelussa, eri maailmojen ajattelua voi olla läsnä samanaikaisesti. Kuten Tall (1999) on todennut, todistusten oletukset riippuvat aina kontekstista. Tässä oletettiin tunnetuiksi "tuttuja laskusääntöjä" sen kummemmin miettimättä, mistä aksioomista nämä tarkalleen seuraavat.

Ilmenevässä ja symbolisessa maailmassa jouduin joka tapauksessa turvautumaan "potentiaalisesti äärettömiin" todistuksiin saadakseni itseni vakuuttuneeksi kaavan oikeellisuudesta. Selvänä erona tälle aksiomaattis-formaalissa maailmassa todistus on "äärellinen" ja tuloksen yleistyminen kaikkia luonnollisia lukuja koskevaksi selittyy sillä, millaiseksi luonnollisten lukujen joukko ymmärretään matematiikan teoriassa. 


\section{Matematiikan kuusi osaa ja niiden välinen vuoropuhelu}

Juha Oikkonen näkee matematiikassa kahdet kasvot, jotka ilmenevät, kun matematiikkaa tehdään "tässä ja nyt" (Oikkonen, 2004). Oikkonen jaottelee matematiikan sosiaalis-subjektiiviseen ja objektiivis-formaaliin puoleen. Matematiikan tekemisen voidaan nähdä olevan (parhaimmillaan) jatkuvaa vuoropuhelua näiden kahden puolen välillä (Oikkonen, 2013). Esimerkiksi funktion jatkuvuuden käsitteellä on sosiaalissubjektiivinen puoli: maalijoukon alkiot ovat lähellä toisiaan silloin, kun lähtöjoukon alkiot ovat lähellä toisiaan ja tämä merkitys näyttäytyy helposti kuvan avulla (ks. Oikkonen, 2004). Mutta käsitteellä on myös objektiivis-formaali puoli, joka perustuu raja-arvon tarkkaan $(\varepsilon, \delta)$-määritelmään: funkio $\mathrm{f}$ on jatkuva pisteessä $\mathrm{x}_{0}$, jos ja vain jos $f\left(x_{0}\right)=$ $\lim _{x \rightarrow x_{0}} f(x)$. Funktion raja-arvo taas määritellään tarkasti seuraavasti: funktiolla f on rajaarvo a pisteessä $\mathrm{x}_{0}\left(\right.$ eli $\left.\lim _{x \rightarrow x_{0}} f(x)=a\right)$, jos ja vain jos jokaisella $\varepsilon>0$ on olemassa sellainen $\delta>0$, että $|f(x)-a|<\varepsilon$ kunhan $0<\left|x-x_{0}\right|<\delta$.

Tämä kahtiajako yhdistettynä Tallin kolmijakoon tuottaa itse asiassa laajemman "matematiikan kuuden osan" viitekehyksen. Oikkonen (2013) on hahmotellut tätä kuuden osan viitekehystä ja pyrin seuraavaksi jäsentämään, mitä tämä voisi tarkoittaa edellisen esimerkin kannalta. Jos piirrän ilmenevään maailmaan kuuluvan kuvan ymmärtääkseni summakaavan, on samaan aikaan käsissäni jotain objektiivista ja jotain subjektiivista. Kuva on objektiivinen siinä mielessä, että kaikki voivat sitä havainnoida ja se on muuttumaton. Toisaalta se, miten kuvassa nähdään matemaattisia ideoita, on subjektiivista. (Lukija voi vielä vilkaista kuviota 1, jossa oli sinisiä ja punaisia ruutuja ja miettiä, millä tavoilla matemaattinen idea siinä näkyy.) Näin ilmenevän maailman ilmiöt voidaan nähdä jakautuvan kahtia. Oikkonen (2013) antaa esimerkiksi tästä kahtiajaosta subjektiiviset mielikuvat ja niiden pohjalta syntyneet sosiaalisesti jaetut pohdinnat sekä objektiiviset matematiikan opetukseen tarkoitetut välineet kuten värisauvat.

Symboliseen maailmaan kuuluvat laskusäännöt ovat jotain täysin objektiivista ja esimerkiksi aiemmin kirjoittamani laskut ovat siis objektiivisesti tosia. Toisaalta myös symboliseen toimintaan liittyy sosiaalis-subjektiivinen puoli; mm. oppijoiden muodostamat miniteoriat (eli "omat laskusäännöt") tuntuvat selvästi kuuluvan tähän. Matematiikan oppimista miniteorioiden näkökulmasta on tutkinut mm. Sinikka Huhtala (ks. Huhtala, 2000). Miniteoriassa voi olla kyse esimerkiksi "väärästä yleistyksestä"; koska

$2(x+y)=2 x+2 y$

voisi paremman tiedon puuttuessa tulla ajatelleeksi että pätee myös

$(x+y)^{2}=x^{2}+y^{2}$ 
Tällaiset miniteoriat ovat luonteeltaan vahvasti subjektiivisia: oppija rakentaa ne itse. Miniteorioiden lisäksi Oikkonen (2013) ehdottaa ns. katumatematiikan kuuluvan symbolisen maailman sosiaalis-subjektiiviseen puoleen.

Aksiomaattis-formaaliin maailman taas ajattelisi olevan oikeastaan täysin objektiivista, mutta myös siihen liittyy sosiaalis-subjektiivinen puoli. Tätä edustaa esimerkiksi matemaatikkojen strateginen metatason keskustelu: "Voisimme käyttää ajatuksia X,Y ja Z asian Ö todistamiseksi." Esimerkiksi tällainen keskustelu on osa matematiikan tekemisen (sosiaalis-subjektiivista) prosessia erona objektiivisille matemaattisille tuloksille. Oikkosen (2013) mukaan kirjoitettu aksiomaattis-formaali matematiikka kuuluu objektiivisformaaliin puoleen ja edellä kuvatun kaltainen keskustelu ja ajattelu sosiaalissubjektiiviseen puoleen.

Taulukko 1 Matematiikan eri osat.

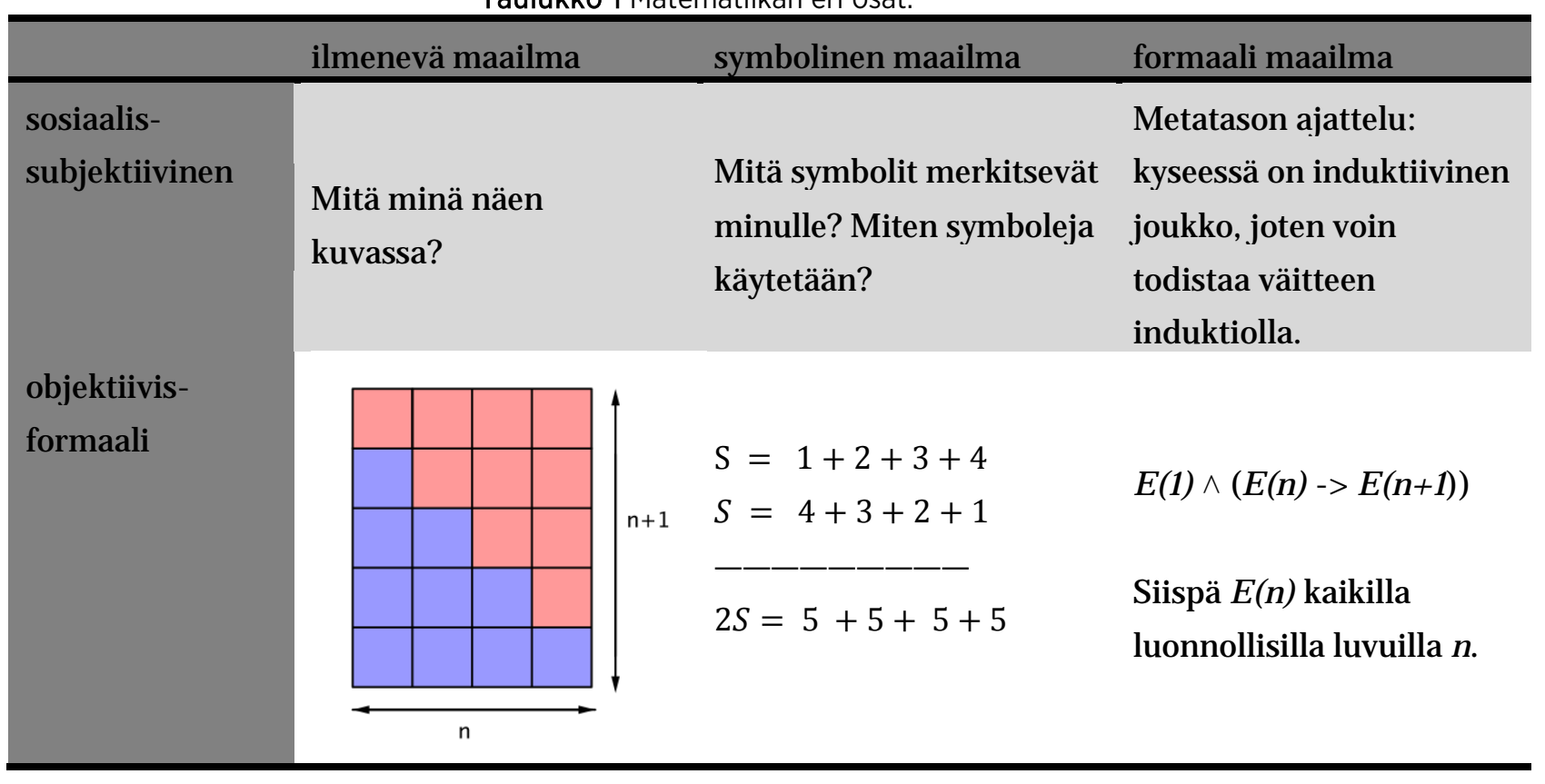

Taulukossa 1 näkyy, miten summakaavaan liittyvä matematiikka jakautuu kuuteen eri osaan. Formaalin maailman sosiaalis-subjektiivista puolta edustaa siis tässä tapauksessa metatason ajattelu siitä, minkälainen käsiteltävä matemaattinen struktuuri on ominaisuuksiltaan ja mitä todistustekniikoita voisi käyttää. Symbolisen maailman sosiaalissubjektiivisessa puolessa on kyse siitä, minkälaisia laskusääntöjä subjekti tuntee ja minkälaisia merkityksiä hän on niille luonut. 


\section{Matematiikan eri osien merkitys oppimisessa}

On monta tapaa "kokea matematiikkaa" ja tehdä sitä itselleen ja muille mielekkääksi. Tutkimukset osoittavat, että mielekkäät matematiikkakokemukset ovat tehokas keino oppijoiden matematiikkakuvan kehittymiseksi toivottuun suuntaan ja toivottujen oppimistulosten saavuttamiseksi (ks. esim. Laine, A. \& Huhtala, S., 2003; Isoda, M \& Tall, D. 2007). Mielekkäät oppimiskokemukset voivat liittyä esimerkiksi symbolisen ja ilmenevän maailman kokonaisvaltaiseen yhdistämiseen (ks. Tall 2013, s.155-174). Kokemukseni mukaan esimerkiksi miniteoriaa "jakolaskussa tulos on aina alkuperäistä pienempi" voi esiintyä monilla oppijoilla. Usein jakolaskua ajatellaan ositusjaon ("jos 10 karkkia jaetaan viidelle ihmiselle, kaikki saavat 2") näkökulmasta. Esimerkiksi 4 : 0,5 =8 näyttäytyy luontevasti sisältöjaon ("jos 10 karkkia jaetaan viiden karkin kokoisiin joukkoihin, joukkoja on 2") näkökulmasta seuraavanlaisella yksinkertaisella kuvalla.
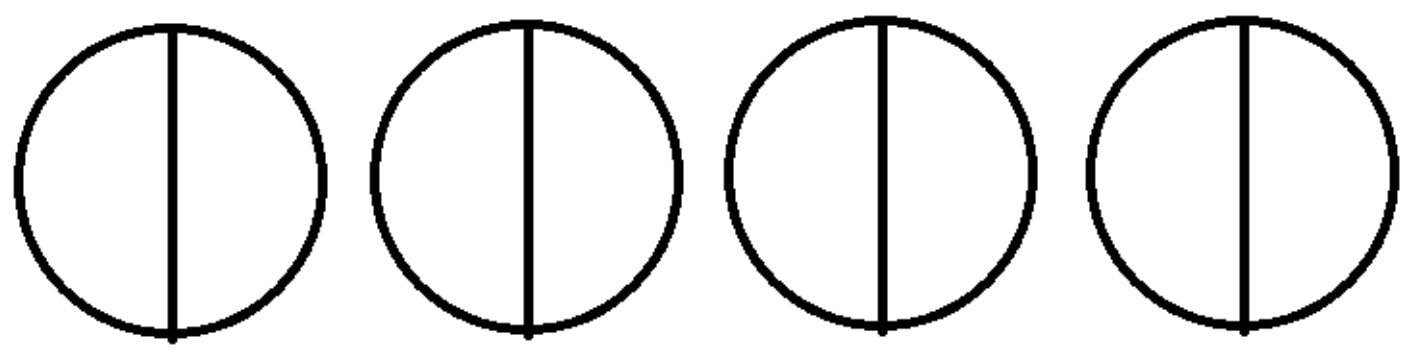

Kuvio 2 Neljä kokonaista jaetaan puolikkaisiin.

Koska matemaattisen ajattelun "juuret" ovat Tallin (2013) mukaan ilmenevän maailman ilmiöissä, edellisten kaltaisten kuvien käyttäminen tarttumapintana opetuksessa voi tuntua jopa itsestään selvältä. Tällaiset kokemukset ovat Tallin mukaan itse asiassa lähestulkoon välttämättömiä, mikäli tavoitellaan pitkän aikavälin oppimista ja käsitteenmuodostusta (Tall, 2006). Aiemman tutkimuksen perusteella vaikuttaa siis siltä, että ilmenevän ja symbolisen maailman ilmiöiden sitominen saumattomaksi kokonaisuudeksi voisi olla syytä ottaa opetukselliseksi tavoitteeksi käytännössä kaikilla koulutustasoilla.

\section{Johtopäätökset}

Edellä esitellyt matematiikan "kuusi osaa" tarjoaa uuden viitekehyksen matemaattisen ajattelun tarkasteluun. Tallin viitekehys on jo entuudestaan matemaattista ajattelua ja sen kehittymistä varsin kokonaisvaltaisesti erotteleva, mutta "kuuden osan" viitekehyksessä tehdään matematiikan objektiivisia ja subjektiivisia puolia eksplisiittisimmiksi. Dubinskya ja McDonaldia (2001) mukaillen matematiikan oppimiseen liittyville teorioille ja malleille voidaan asettaa ainakin seuraavia tavoitteita: 
- malli kykenee ennustamaan tutkittavia ilmiöitä,

- malli on selitysvoimainen,

- mallia voidaan käyttää monen eri ilmiön yhteydessä,

- malli auttaa monimutkaisten ilmiöiden jäsentämisessä,

- malli tarjoaa välineen datan analysointiin ja

- malli tarjoaa sellaisia puhetapoja ja erotteluja oppimisesta, jotka ovat rikkaampia kuin pelkät pinnalliset kuvaukset.

Esimerkiksi miniteorioiden näkökulma asettuu tässä matematiikan kuuden osan mallissa yhdeksi osaksi (symbolisen maailman sosiaalis-subjektiivinen osa) laajempaa matemaattisen ajattelun kenttää, mikä tekee viitekehyksestä Tallin kolmea maailmaa laajemman ja tutkittavaa ilmiötä tarkemmin jäsentävän. Mikäli esimerkiksi opetuksen tavoitteeksi asetetaan ensimmäisen ja toisen maailman ilmiöiden sitomista toisiinsa, tällä viitekehyksellä on hyvä selitysvoima oppimisprosessin suhteen. Oppimisprosessin kuvaamiseen voidaan tarvita tapauksesta riippuen edelleenkin jotain spesifisempää, kuten aiemmin mainittu APOS-teoria, mutta hahmoteltu viitekehys tarjoaa jo itsessään mahdollisuuksia oppimisprosessin kuvaamiseen (kuten muutokset oppijan symboleihin assosioimissa merkityksissä).

\section{Lähteet}

Dubinsky, E. \& McDonald, M. A. (2001). APOS: A constructivist theory of learning in undergraduate mathematics education research. Teoksessa D. Holton (toim.), The teaching and learning of mathematics at university level: An ICMI study. Dordrecht: Kluwer Academic Publishers.

Gray, E. \&Tall, D. (1991). Duality, Ambiguity \& Flexibility in Successful Mathematical Thinking, PME 15, Assisi, 2 72-79.

Huhtala, S. (2000). Lähihoitajaopiskelijan oma matematiikka. Helsingin yliopiston opettajankoulutuslaitos. Tutkimuksia 219.

Isoda, M. \& Tall, D. (2007). Long-term development of Mathematical Thinking and Lesson Study. Verkkodokumentti. < http:// homepages.warwick.ac.uk/staff/David.Tall/pdfs/dot2007x-tallisoda-lessonstudy.pdf $>$ Luettu 18.10.2013.

Laine, A. \& Huhtala, S. (2003). J akolaskun ymmärtäminen osana oppilaan matematiikkakuvaa. J ulkaisussa: NMI-bulletin. 2003, 4, s. 9-17.

Lampinen, A. (2008). Entäpä jos huonoa laskupäätä ei olekaan! Verkkodokumentti. $<$ http:// www.varganemenyi.fi/includes/menetelma.php> Luettu 7.10.2013. 
Mura, R. (1993). Images of mathematics held by university teachers of mathematical sciences. Educational Studies in Mathematics, 25 (4), 375-385.

Oikkonen, J . (2004). Mathematics between its two faces, Matemaattisten aineiden opettajan taitotieto - haste vai mahdollisuus, L. J alonen, T. Keranto and K. Kaila (toim.), Oulun yliopisto, pp. 23-30, ISBN 951-42-7886-0.

Oikkonen, J . (2013). A visual construction for a nowhere differentiable function. J ulkaisematon käsikirjoitus.

Tall, D. (2013) How Humans Learn to Think Mathematically. Cambridge University Press.

Tall, D. (2006) Encouraging Mathematical Thinking that has both power and simplicity. Verkkodokumentti. <http:// homepages.warwick.ac.uk/ staff/David.Tall/pdfs/dot2006h-tokyoplenary.pdf> Luettu 24.10.2013.

Tall, D. (2004). Thinking through three worlds of mathematics. Proceedings of the 28th Conference of the International Group for the Psychology of Mathematics Education, Bergen, Norja, 4, 281288.

Tall, D. (1999). The chasm between thought experiment and mathematical proof. Teoksessa G. Kadunz, G. Ossimitz. W. Peschek, E. Schneider, B. Winkelmann (toim.), Mathematische Bildung und neue Technologien, Teubner, Stuttgart, 319-343. 
